\title{
Autonomic Dysfunction as a Delayed Sequelae of Acute Ethylene Glycol Ingestion
}

\author{
A Case Report and Review of the Literature
}

\author{
Sayed S. Rahman • Satish Kadakia • Leah Balsam • \\ Sofia Rubinstein
}

Published online: 17 November 2011

(C) American College of Medical Toxicology 2011

\begin{abstract}
Ethylene glycol poisoning is a common form of poisoning worldwide. The clinical course of ethylene glycol poisoning usually follows a three-stage progression, although these stages may overlap. A fourth stage of delayed neurological dysfunction consisting of cranial neuropathies has been suggested in several case reports. We describe a patient with unique findings of postural hypotension and gastroparesis following ethylene glycol toxicity with the additional uncommon features of albuminocytologic dissociation and increased intracranial pressure with papilledema. In addition, we provide a review of the literature on delayed neurological manifestations in ethylene glycol toxicity and further elucidate a description of a fourth stage of delayed neurological dysfunction following ethylene glycol poisoning.
\end{abstract}

Keywords Ethylene glycol poisoning $\cdot$ Neurological sequelae $\cdot$ Autonomic dysfunction $\cdot$ Postural hypotension . Gastroparesis

\section{Introduction}

Ethylene glycol (EG) poisoning is a relatively common occurrence worldwide that can lead to significant morbidity

S. S. Rahman $(\varangle) \cdot$ L. Balsam $\cdot$ S. Rubinstein

Department of Medicine,

Division of Nephrology and Hypertension,

Nassau University Medical Center,

2201 Hempstead Turnpike, Box 49, East Meadow,

NY 11554, USA

e-mail: drshakee199@yahoo.com

S. Kadakia

Department of Neurology, Nassau University Medical Center,

East Meadow, NY, USA and mortality [1]. Ethylene glycol $\left(\mathrm{C}_{2} \mathrm{H}_{6} \mathrm{O}_{2}\right)$ has a small molecular weight enabling it to increase the osmol gap early in toxic ingestions. However, it is EG's metabolism in the liver and the production of its toxic metabolites (glycoaldehyde, glycolic acid, glyoxalate, and oxalate) that are responsible for most of the clinical manifestations of poisoning.

The clinical course of ethylene glycol poisoning usually follows a three-step progression, the stages of which may overlap considerably $[2,3]$ :

Stage 1 ( 0.5 to $12 \mathrm{~h}$ post ingestion) consists of central nervous system (CNS) symptoms of inebriation, ataxia, seizure, coma and, with large enough doses, death. Irritation to the stomach may cause nausea and vomiting.

Stage 2 (12 to $24 \mathrm{~h}$ post ingestion) is a result of accumulation of organic acids leading to cardiopulmonary syndrome that manifests as tachycardia, hypertension, tachypnea and pulmonary edema (cardiogenic and noncardiogenic).

Stage 3 (24 to $72 \mathrm{~h}$ post ingestion) consists of renal failure resulting from osmotic damage and calcium oxalate deposition in the kidney. Metabolic acidosis can be found in all three stages of EG poisoning.

An additional stage four (days to weeks after ingestion) that manifests as delayed neurological deficits was originally suggested by Factor and Lava [4] in 1987 based on three case reports exhibiting cranial nerve deficits [5-7] following EG poisoning. The manifestation of this finding was likely due to better survival outcomes of severe EG poisoning which was often fatal in the first three phases before widespread use of hemodialysis. Since then, there have been other cases reporting findings of delayed cranial neuropathies [8-19]. Reports also describe cerebral edema [20, 21], seizures [20, 22], increased intracranial pressure with 
papilledema [16] and communicating hydrocephalus [11], stroke [14, 23, 24] (one of which involved development of rapid onset Parkinson disease due to basal ganglia hemorrhagic infarction [24]), diaphragmatic paralysis [13], sensory radiculopathies [10, 12, 17, 25], cerebrospinal fluid (CSF) findings of albuminocytologic dissociation [4, 9, 13, 25] as well as aseptic meningitis $[8,21,26]$. Some features of autonomic nervous system (ANS) dysfunction such as the bradycardia/tachycardia syndrome [14] and urinary retention with paralytic ileus [17] were reported; however, to our knowledge, postural hypotension and confirmed gastroparesis have not been previously described. Vomiting with delayed transit by barium follow through [12] has been reported; however, this is not a confirmatory test for gastroparesis and could represent a paralytic ileus. We report a case of EG poisoning that resulted in ANS dysfunction with postural hypotension and confirmed gastroparesis with the additional uncommon features of albuminocytologic dissociation (as seen in Guillain-Barre syndrome) and increased intracranial pressure with papilledema. We provide a review of late neurological manifestations of EG poisoning and further characterize a fourth stage of this illness consisting of delayed neurological dysfunction.

\section{Case Report}

An 18-year-old white male with a history of depression was brought to the emergency department in a state of confusion and agitation. His suicidal note stated that he had ingested half a gallon of ethylene glycol $10 \mathrm{~h}$ prior. On presentation he was tachycardic at 109 beats $/ \mathrm{min}$, his blood pressure was $178 / 100 \mathrm{mmHg}$ and his respiratory rate was 22 breaths/min. $\mathrm{He}$ appeared combative and confused; the rest of the physical examination including his neurological examination was unremarkable. The patient was intubated for airway control and $100 \mathrm{~g}$ of activated charcoal was given via a nasogastric tube. Initial laboratory studies revealed a leukocytosis of 27,000 per $\mathrm{cm}^{3}$, blood urea nitrogen (BUN) of $11 \mathrm{mg} / \mathrm{dl}$, serum creatinine concentration of $1.5 \mathrm{mg} / \mathrm{dl}$, glucose of $145 \mathrm{mg} / \mathrm{dl}$, serum sodium $(\mathrm{Na})$ was $141 \mathrm{mmol} / \mathrm{l}$, chloride $(\mathrm{Cl})$ was $104 \mathrm{mmol} / \mathrm{l}$ and bicarbonate $\left(\mathrm{HCO}_{3}\right)$ of $6 \mathrm{mmol} / \mathrm{l}$ (anion gap was 31). An arterial blood gas was significant for evidence of metabolic acidosis with a serum $\mathrm{pH}$ of 7.05 and a $\mathrm{PCO}_{2}$ of $35 \mathrm{mmHg}, \mathrm{HCO}_{3}$ of $9.5 \mathrm{mmol} / \mathrm{l}$, and a serum lactate of $9.7 \mathrm{mmol} / \mathrm{l}$. His measured serum osmolality was $356 \mathrm{mOsm} / \mathrm{kg}$, his calculated serum osmolarity was $294 \mathrm{mOsm} / 1$ yielding an osmol gap of $62 \mathrm{mOsm} / \mathrm{kg}$. His serum alanine aminotransferase (ALT) was 72 units/dl, aspartate aminotransferase (AST) was 50 units/dl and a total bilirubin was $0.8 \mathrm{mg} / \mathrm{dl}$. A serum toxicology screen for acetaminophen, salicylate, ethanol, and methanol was negative. A serum EG concentration was
$1958 \mu \mathrm{g} / \mathrm{ml}(195 \mathrm{mg} / \mathrm{dl})$. An electrocardiogram (EKG) was remarkable for sinus tachycardia of 109 beats/min and his chest radiograph was within normal limits. He was started on a continuous intravenous infusion of bicarbonate, was given appropriate intravenous doses of fomepizole (loading dose of $1.6 \mathrm{~g}$ followed by a maintenance dose of $1.1 \mathrm{~g}$ every $12 \mathrm{~h}$ for an additional two doses), and single doses of folate $(100 \mathrm{mg})$, thiamine $(100 \mathrm{mg})$ and pyridoxine $(50 \mathrm{mg})$. The patient was emergently hemodialyzed for EG poisoning $5 \mathrm{~h}$ after initial presentation. Over the ensuing $16 \mathrm{~h}$, the patient became anuric with a rising serum creatinine concentration. His metabolic acidosis progressively improved $\left(\mathrm{pH} 7.38, \mathrm{pCO}_{2} 35 \mathrm{mmHg}, \mathrm{HCO}_{3}\right.$ $23 \mathrm{mmol} / \mathrm{l}$ ) and serum osmolality improved to $284 \mathrm{mOsm} / \mathrm{kg}$. The patient was extubated $39 \mathrm{~h}$ after presentation to the ER. Hemodialysis was continued for his renal failure.

On day 13 of his hospitalization, the patient complained of a headache, photophobia, and blurring of vision with diplopia. Ophthalmological and neurological examinations revealed bilateral papilledema with normal visual acuity and a left sixth cranial nerve palsy. A lumbar puncture revealed a raised opening CSF pressure of $31 \mathrm{~cm}$ of $\mathrm{H}_{2} \mathrm{O}$ (normal $<21 \mathrm{~cm}$ of $\mathrm{H}_{2} \mathrm{O}$ ), a glucose of $61 \mathrm{mg} / \mathrm{dl}$, a protein of $157 \mathrm{mg} / \mathrm{dl}$ and zero white blood cells (albuminocytologic dissociation). Magnetic resonance imaging (MRI) with gadolinium of the patient's head was within normal limits. The patient was started on acetazolamide to treat his elevated intracranial pressure with papilledema. One week later, the patient developed a left seventh cranial nerve palsy, and evidence of a sensory neuropathy in both feet (sharp pain and parasthesias on plantar surfaces). Strength, deep tendon reflexes, sensation to touch, temperature and vibration were all normal. Gabapentin was initiated to treat the neuropathy with improvement in symptoms noted.

In addition, the patient started to complain of dizziness on standing and was found to have postural hypotension (supine BP, 141/81 mmHg, standing BP, 108/66 mmHg) which did not resolve despite discontinuing his antihypertensive medications (labetolol and amlodipine). He also complained of persistent nausea and vomiting after meals. A gastric emptying study done 4 weeks after initiation of gastrointestinal symptoms showed mildly delayed gastric emptying of $111 \mathrm{~min}$ (normal, up to $90 \mathrm{~min}$ ). His symptoms improved on oral metoclopromide of $10 \mathrm{mg}$ every $6 \mathrm{~h}$ as needed.

Hemodialysis was discontinued 40 days after the initial presentation due to recovery of renal function and the patient was discharged home. The sixth and seventh cranial nerve palsies, papilledema, sensory radiculopathies and gastroparesis gradually resolved by 3 weeks after discharge; however, he continued to have asymptomatic orthostatic hypotension off all medications. 


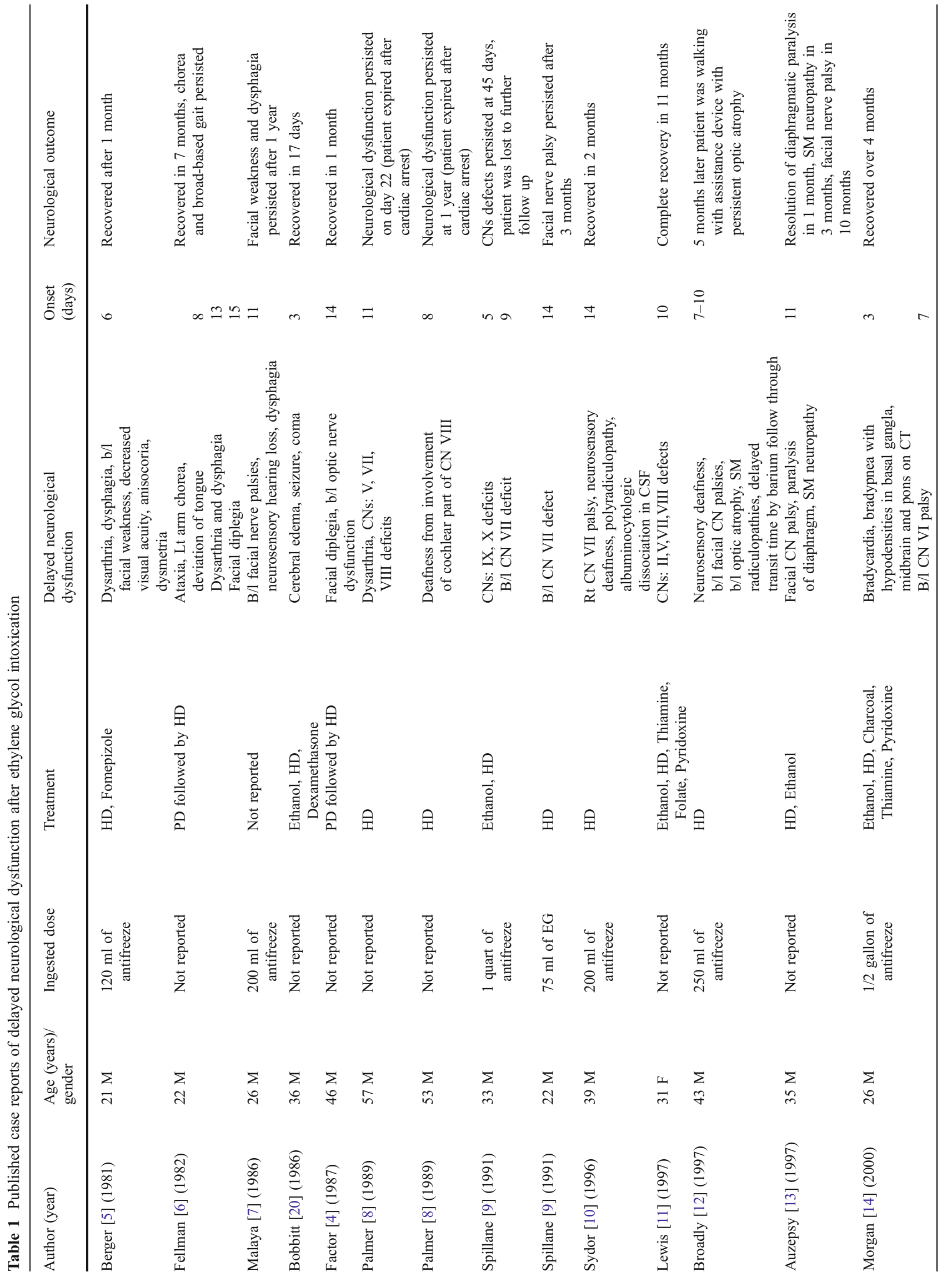




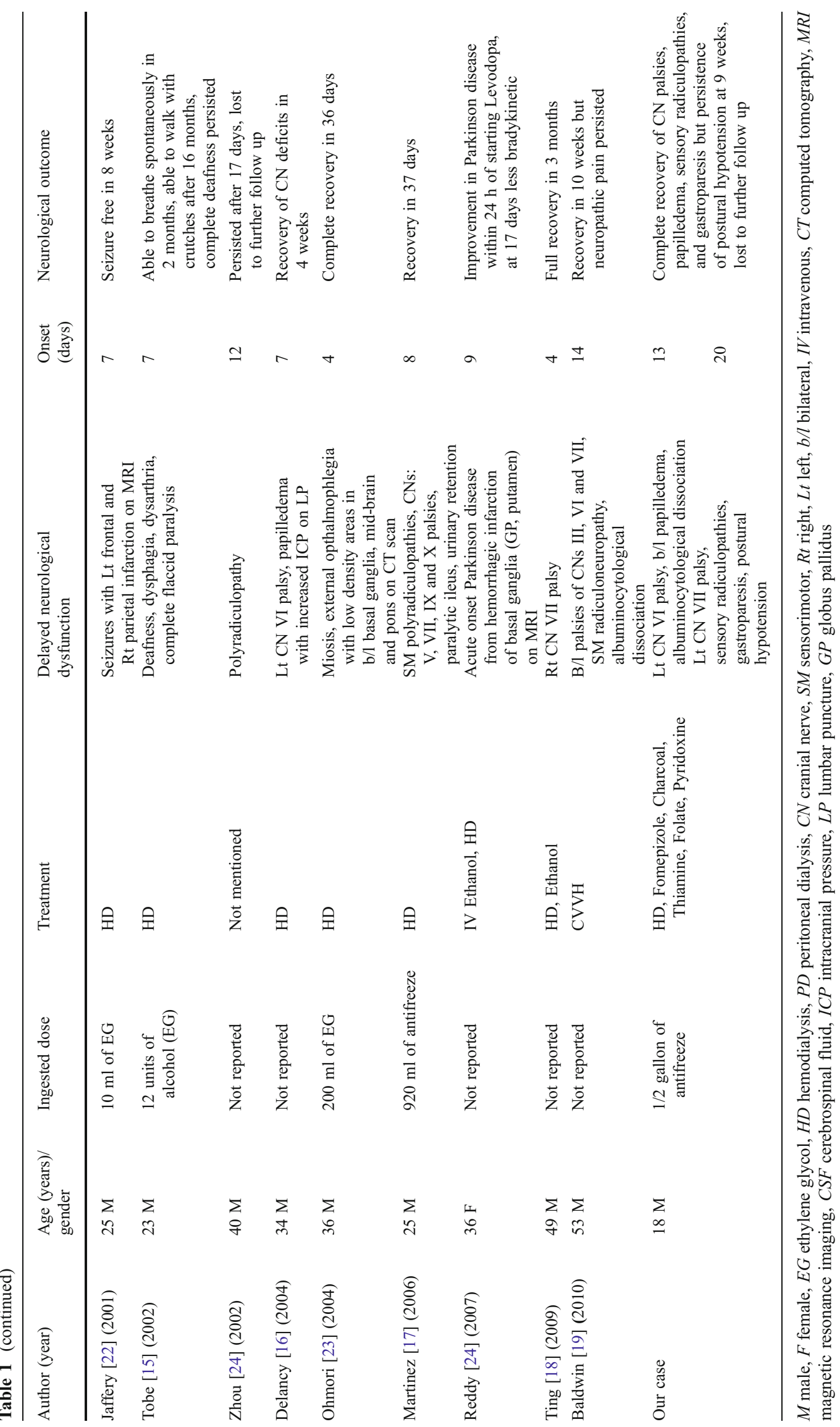




\section{Discussion}

Our patient had evidence of ANS dysfunction in the form of radiologically confirmed gastroparesis and postural hypotension; this has not been previously reported as a complication of EG poisoning. None of his medications are known to cause postural hypotension. He received supplemental thiamine and pyridoxine to replenish the respective cofactors during his early hospitalization; thus ruling out their deficiencies as a cause of his neuropathy. Our patient also had the additional uncommon features of albuminocytologic dissociation and increased intracranial pressure with papilledema. This has been described previously in only a few cases as delayed neurotoxicity following EG intoxication.

The originally reported delayed cranial nerves abnormal signs and symptoms occurring five to 20 days later [11] are unlikely to be explained by the immediate formation of toxic metabolites. Similarly, since tissue deposition (particularly in the kidneys, brain and lungs) of calcium oxalate crystals occurs within 3 to $6 \mathrm{~h}$ of ethylene glycol ingestion [11], the direct deposition of calcium oxalate crystals in the tissues is also an unlikely explanation. Oxalate is a strong reducing agent and is toxic to endothelial cells [21]. Deposition of calcium oxalate crystals in cases of EG poisoning has been documented within small cerebral blood vessels walls and leptomeninges at post-mortem examinations [21, 26]. In 1979, Levinsky et al. [26] demonstrated deposition of calcium oxalate crystals in the walls of cerebral vessels with an infiltrate of neutrophils and mononuclear cells as well as proteinaceous fluid in the meninges and around parenchymal vessels. These changes can result in patchy focal necrosis with or without hemorrhage throughout the brain and chemical meningitis [26]. More recently, Froberg et al. [21] also found calcium oxalate crystals within vessel walls with prominent perivascular edema and collection of polymorphonuclear leukocytes adjacent to these vessels. Histologic evaluation of tissue sections of meninges showed a neutrophilic infiltrate [21]. Both autopsy investigations following EG poisoning have shown edema, hemorrhage and perivascular inflammation adjacent to small blood vessels in the brain suggesting exudative damage to the endothelial cells in these vessels causing nerve dysfunction $[21,26]$. The time required to develop an inflammatory response to the endothelial injury may explain the delay in neurological sign and symptom manifestations [11, 21] (Table 1 [4-24]).

The ANS dysfunction, sensory radiculopathy and CSF finding of albuminocytologic dissociation observed in our patient likely resulted from vascular involvement and injury to the corresponding brain structures. His ANS dysfunction signs and symptoms may have resulted from involvement of the hypothalamus or vasomotor center [14]. The sensory radiculopathy and CSF findings may have resulted from meningial involvement covering the nerve roots.
The clinical outcome of patients reported to have developed these delayed neurological findings is variable (Table 1) [424]. An overwhelming majority of patients who developed the fourth phase of EG toxicity were males (22 cases out of total 24). In those patients in whom treatment was reported, all underwent dialysis. The initial onset of delayed neurological symptoms varied from 3 to 20 days (confirming observation made by Lewis et al. [11]) with an average of 9 days after ingestion of EG. A significant number of patients recovered their neurological function in 1 to 2 months after onset; in some patients the neurological deficits took longer to resolve and yet in others the neurological dysfunction persisted at 1 year of follow-up. The fastest recovery of neurological manifestations (17 days) was observed in a case treated with Dexamethasone [20].

We hypothesize that the fourth phase of delayed neurological dysfunction is not limited to cranial nerve deficits but encompasses all features of neurological dysfunction and stems from the inflammatory response due to endothelial injury from calcium oxalate deposition.

In conclusion, physicians treating patients with EG poisoning should be aware of the potential for delayed neurotoxicity. Autonomic nervous system dysfunction manifesting as postural hypotension and gastroparesis can be associated with EG poisoning and should be recognized as part of the delayed neurological complications that can manifest after recovery from acute poisoning. More research is indicated to further elucidate the etiology of the neurological component of this illness.

Conflict of Interests None for all authors.

\section{References}

1. Watson WA, Litovitz TL, Klein-Schwartz W, Rodgers GC Jr, Youniss J, Reid N, Rouse WG, Rembert RS, Borys D (2004) 2003 annual report of the American Association of Poison Control Centers Toxic Exposure Surveillance System. Am J Emerg Med 22(5):335

2. Eder AF, McGrath CM, Dowdy YG, Tomaszewski JE, Rosenberg FM, Wilson RB, Wolf BA, Shaw LM (1998) Ethylene glycol poisoning: toxicokinetic and analytical factors affecting laboratory diagnosis. Clin Chem 44:168

3. Kraut JA, Kurtz I (2008) Toxic alcohol ingestions: clinical features, diagnosis, and management. Clin J Am Soc Nephrol 3:208

4. Factor SA, Lava NS (1987) Ethylene glycol intoxication: a new stage in clinical syndrome. NY State J Med 87:179

5. Berger JR, Ayyar RA (1981) Neurological complication of ethylene glycol intoxication. Report of a case. Arch Neurol 38:724

6. Fellman DM (1982) Facial diplegia following ethylene glycol. Arch Neurol 39:739

7. Mallya KB, Mendis T, Guberman A (1986) Bilateral facial paralysis following ethylene glycol ingestion. Can J Neurol Sci 13(4):340

8. Palmer BF, Eigenbrodt EH, Henrich WL (1989) Cranial nerve deficit: a clue to the diagnosis of ethylene glycol poisoning. Am J Med 87(1):91 
9. Spillane L, Roberts JR, Meyer AE (1991) Multiple cranial nerve deficits after ethylene glycol poisoning. Ann Emerg Med 20:208

10. Sydor A, Kolasa M (1996) Late complications after ethylene glycol poisoning — case history. Przegl Lek 53(3):190

11. Lewis LD, Smith BW, Mamourian AC (1997) Delayed sequelae after acute overdoses or poisonings: cranial neuropathy related to ethylene glycol ingestion. Clin Pharmacol Ther 61:69

12. Broadley SA, Ferguson IT, Walton B, Tomson CR (1997) Severe sensorimotor polyradiculoneurophathy after ingestion of ethylene glycol. J Neurol Neurosurg Psychiatry 63(2):261

13. Auzépy P, Masnou P, Métral S, Foucher R, Charpentier B (1997) Diaphragm paralysis and facial diplegia with albumin-cell count dissociation in acute ethylene glycol poisoning. Presse Med 26 (18):856

14. Morgan BW, Ford MD, Follmer R (2000) Ethylene glycol ingestion resulting in brainstem and midbrain dysfunction. J Toxicol Clin Toxicol 38(4):445

15. Tobé TJ, Braam GB, Meulenbelt J, van Dijk GW (2002) Ethylene glycol poisoning mimicking Snow White. Lancet 359(9304):444

16. Delany C, Jay WM (2004) Papilledema and abducens nerve palsy following ethylene glycol ingestion. Semin Ophthalmol 19(34):72

17. Martínez Miguel P, Rengel MA, Ortega M, Rodríguez Ferrero M, Goicoechea M, Verde E, Muñoz-Blanco JL, Luño J (2006) Prolonged acute renal failure and severe polyradiculopathy in ethylene glycol intoxication. Nefrologia 26(6):738
18. Ting SM, Ching I, Nair H, Langman G, Suresh V, Temple RM (2009) Early and late presentations of ethylene glycol poisoning. Am J Kidney Dis 53(6):1091

19. Baldwin F, Sran H (2010) Delayed ethylene glycol poisoning presenting with abdominal pain and multiple cranial and peripheral neuropathies: a case report. J Med Case Rep 4:220

20. Bobbit WH, Williams RM, Freed CR (1986) Severe ethylene glycol intoxication with multisystem failure. West J Med 144:225

21. Froberg K, Dorion RP, McMartin KE (2006) The role of calcium oxalate crystal deposition in cerebral vessels during ethylene glycol poisoning. Clin Toxicol 44:315

22. Jaffery JB, Aggarwal A, Ades PA, Welse WJ (2001) A long sweet sleep with sour consequences. Lancet 358(9289):1236

23. Ohmori K, Kumada K, Kimura F, Ishihara S, Fukuda M, Suzuki K, Kohama A (2004) Ethylene glycol poisoning complicated by central nervous system abnormalities. Chudoku Kenkyu 17(4):365

24. Reddy NJ, Lewis LD, Gardner TB, Osterling W, Eskey CJ, Nierenberg DW (2007) Two cases of rapid onset Parkinson's syndrome following toxic ingestion of ethylene glycol and methanol. Clin Pharmacol Ther 81(1):114

25. Zhou L, Zabad R, Lewis RA (2002) Ethylene glycol intoxication: electrophysiological studies suggest a polyradiculopathy. Neurology 59(11):1809

26. Levinsky NG, McCluskey RT, Ropper AH, Daniel TO, Brodsky GL (1979) Case records of the Massachusetts General Hospitalcase 38-1979. N Engl J Med 301:650 